IBIMA Publishing

JMED Research

http://www.ibimapublishing.com/journals/JMED/jmed.html

Vol. 2013 (2013), Article ID 608765, 12 pages

DOI: $10.5171 / 2013.608765$

Research Article

\title{
Monosodium Glutamate Toxic Effects and Their Implications for Human Intake: A Review
}

\author{
Veronika Husarova and Daniela Ostatnikova
}

Institute of Physiology, Faculty of Medicine, Comenius University, Bratislava, Slovakia

Correspondence should be addressed to: Veronika Husarova; nika.husarova@gmail.com

Received 13 October 2013; Accepted 19 November 2013; Published 27 December 2013

Academic Editor: Umit Arslan

Copyright (c) 2013 Veronika Husarova and Daniela Ostatnikova. Distributed under Creative Commons CC-BY 3.0

\begin{abstract}
Monosodium Glutamate (MSG) is one of the world's most widely used food additives. Its toxic effects have been shown in numerous animal studies, however in most of them, the method of administration and the doses were not similar to human MSG intake. In this paper we review animal and human studies in which MSG effects on central nervous system, adipose tissue and liver, reproductive organs and other systems have been shown and we discuss their implications for human MSG intake.
\end{abstract}

Keywords: Food additives, obesity, Chinese restaurant syndrome.

\section{Introduction}

Monosodium Glutamate (MSG) is one of the world's most extensively used food additives which is ingested as part of commercially processed foods. As a flavor enhancer, MSG increases the sapidity of food. MSG produces a flavor that cannot be provided by other foods. It elicits a taste described in Japanese as umami, which is translated to "savory" (Birks 2005). In 1991, the average intake of MSG in United Kingdom was 580 mg/day for general population individual and $4.68 \mathrm{~g} /$ day for extreme users (Rhodes et al. 1991). The estimated average daily MSG intake per person in industrialized countries is 0.3$1.0 \mathrm{~g}$, but it depends on the MSG content in foods and an individual's taste preferences (Geha et al. 2000). According to a joint inquiry by the governments of Australia and
New Zealand in 2003, a typical Chinese restaurant meal contains between 10 and $1500 \mathrm{mg}$ of MSG per $100 \mathrm{~g}$ (Freeman 2006). The oral dose that is lethal to $50 \%$ of subjects $\left(\mathrm{LD}_{50}\right)$ in rats and mice is 15.000$18.000 \mathrm{mg} / \mathrm{kg}$ body weight (Walker and Lupien 2000).

Studies providing the evidence of MSG toxic effects have raised the increasing interest in MSG intake as flavor enhancer. Neurotoxic effects in brain, obesity and metabolic defects, "Chinese restaurant syndrome“ and detrimental effects on sex organs are the most discussed in the connection with MSG intake. We briefly review the studies about MSG effects and its potential pathological influence on different systems in humans.

Cite this Article as: Veronika Husarova and Daniela Ostatnikova (2013), "Monosodium Glutamate Toxic Effects and Their Implications for Human Intake: A Review," JMED Research, Vol. 2013 (2013), Article ID 608765, DOI: $10.5171 / 2013.608765$ 


\section{Central Nervous System}

Glutamate is the excitatory neurotransmitter in the mammalian central nervous system (CNS) playing an important role in both physiological and pathological processes (Mattson 2008). Glutamate receptors include three families of ionotropic receptors (NMDA - N-methyl-D-aspartate, AMPA - $\alpha$-amino-3hydroxy-5-methyl-4-isoxazolepropionic acid and kainate) and three groups of metabotropic receptors (mGluR) (Meldrum 2000). They are dispersed throughout the central nervous system including amygdala, hippocampus and hypothalamus where they regulate many vital metabolic and autonomic functions (Collison et al. 2012).

MSG is used as an agent which in high doses causes neuronal necrosis in hypothalamic arcuate nuclei in neonatal rats (Pelaez et al. 1999). However, MSG effects are more extensive and not limited to hypothalamic area. MSG (4 mg/g, subcutaneously, on postnatal days 1, 3, 5 and 7) led to prefrontal cerebral cortex changes, including fewer neurons, shorter and less ramified dendritic processes (Gonzalez-Burgos et al. 2001) and loss of cortical cell number from postnatal day 8-14 compared to control rats (RiveraCervantes et al. 2004). The same dose of MSG injected subcutaneouslyon days $2,4,6,8$, and 10 of postnatal life resulted in $30 \%$ and $40 \%$ reduction of pituitary weight in ages of 6 and 12 months respectively (Miskowiak and Partyka 2000). Pituitary weight affection seems to be connected with its function derangement. Increased proopiomelanocortin mRNA levels and adrenocorticotropic hormone concentration in the adenopituitary have been found in neonatal MSG-treated rats compared with controls $(4 \mathrm{mg} / \mathrm{g}, 5$ administrations intraperitoneally) (Skultetyova et al. 1998). Furthermore, numerous studies have shown that neonates treated with MSG exhibited neuronal cell death with reduction of photoreceptor and glial cells (Blanks et al. 1981, Reif-Lehrer et al. 1975, Regan et al. 1981, Hyndman and Adler 1981).
Although the toxic effects of MSG on the CNS have been shown in previously mentioned animal studies, there are problems to apply these results' to human MSG intake. Subcutaneous or intraperitoneal MSG administration in rats can be hardly compared with peroral intake of MSG. FAO/WHO Expert Committee on Food Additives (JECFA) in 1988 noted that blood levels of glutamate associated with lesions of the hypothalamus in the neonatal mouse were not approached in humans even after bolus doses of $10 \mathrm{~g}$ MSG in drinking water (Meldrum 2000). No pathological changes in the hypothalamic arcuate nuclei of pregnant and lactating female rats and their fetuses, sucklings, and weanling mice were observed after MSG intake in diet $(14.0,42.8$ or 42.0 $\mathrm{g} / \mathrm{kg}$ ) (Takasaki 1978). This can be explained by the results of the study in pigs which has shown that less than $5 \%$ of ingested glutamate was absorbed from the gut into the portal blood (Reeds et al. 1996). However, contradictory results in different brain areas have been found in male albino rats fed by a lower dose of MSG ( $3 \mathrm{~g} / \mathrm{kg} /$ day) mixed with their foods for 14 days. Histological examination of cerebellar cortex showed degenerative changes as pyknotic Purkinje and granule cells with areas of degeneration surrounded by inflammatory cells in granular layer (Hashem et al. 2012).

Inconsistency in above mentioned results requires further research to elucidate the mechanisms of MSG action in the CNS after absorption in humans. Moreover, the ingested glutamate effects on CNS must be researched also in its connection with signalling from the gastrointestinal tract. In rats, activation of both the gastric and the celiac branches of the vagus nerve led to the activation of the insular cortex, limbic system, hypothalamus and nucleus tractus solitaries. Furthermore, as a result of postingestive effects, MSG was able to induce flavor-preference learning (Bannai and Torii 2013). 
The next important difference between rodent and human MSG intake is a period of life with regard to neuronal development. It was suggested that MSG excitotoxicity occurs only when the blood-brain barrier is vulnerable, for example in neonates (Matyskova et al. 2008). JECFA in 1988 suggested that ingestion of MSG was not associated with elevated levels in maternal milk and glutamate did not readily pass the placental barrier (Walker and Lupien 2000). Also the Consensus meeting in 2007 noted that glutamate did not trespass into fetal circulation, even in high doses (Beyreuther et al. 2007). However, the opposite findings have been shown in animal studies and the glutamate neurotoxicity in newborns with the behavioral effects rather than structural or histological changes remains in question. Kunming filial mice which mothers treated with MSG (2.5 mg/g or $4.0 \mathrm{mg} / \mathrm{g}$ body weight) per os in 17-21 days of pregnancy had significantly impaired Y-maze discrimination learning in the 60.day, although the neuronal damage of the periventricular organs or the hypothalamus was not observed (Yu et al. 1997). Moreover, subneurotoxic doses of MSG $(2 \mathrm{mg} / \mathrm{g}$, for 10 days) given perorally to rat neonates led to significant decrease in the active avoidance learning performance at the 90thpost-dosing day, which indicates that early-life MSG exposure could lead to subtle behavioral aberrations in adulthood (Ali et al. 2000).

One of the most important problems in the application of the results of animal studies to human dietary MSG effects are the differences between doses administered to animals and those ingested in food of a human as a flavor enhancer. The lowest dose in the previously mentioned studies was 2 $\mathrm{g} / \mathrm{kg}$ of body weight that corresponds to an ingestion of $140 \mathrm{~g}$ in a $70 \mathrm{~kg}$ man, while the average daily intake of MSG is estimated to be 0.3-1.0 g (Geha et al. 2000). Thus, further animal studies focused on MSG effects on the CNS in diet should equalize the doses to human intake. Further research should be done to elucidate the behavioral effects of peroral intake of MSG in various doses and potentially different influence of MSG on fetal, neonatal and adult brain structures in humans.

\section{Obesity and Metabolic Disturbances}

Data from animal studies, in which neonatal administration of MSG provides a model of obesity with impaired glucose tolerance and insulin resistance led to concerns about obesity in humans using MSG in food. More hypotheses have proposed the mechanisms of MSG influence on metabolism. The potential link between MSG and obesity includes the MSG effect on energy balance by increasing palatability of food and by disrupting the hypothalamic signaling cascade of leptin action (He et al. 2011, Hermanussen and Tresguerres 2003). The inflammatory basis of MSG-induced obesity was demonstrated in the $19^{\text {th }}$ weeks old rats which were treated by subcutaneous injections of $2 \mathrm{mg} / \mathrm{g}$ of MSG on postnatal days 2 and 4 and by subcutaneous injections of $4 \mathrm{mg} / \mathrm{g}$ on postnatal days 6,8 and 10. MSG increased mRNA expression of interleukin-6, tumor necrosis factor-alpha, resistin and leptin in visceral adipose tissue, it increased insulin, resistin and leptin levels in serum and it also impaired glucose tolerance (Roman-Ramos et al. 2011). As liver transaminases were severely depressed, authors hypothesized that MSG could induce liver injury likely as a consequence of incipient nonalcoholic steatohepatitis, contributing to inflammation (Roman-Ramos et al. 2011). The associations of liver alterations with adipose tissue metabolism in nonalcoholic steatohepatitis after dietary MSG have been also shown at 32 weeks of age C57BL/6J mice which mothers were fed by low-dose dietary monosodium glutamate $(0.64 \mathrm{~g} / \mathrm{l} ; 97 \mathrm{mg} / \mathrm{kg})$ throughout gestation and were weaned onto the same diet. MSG increased the expression of several genes implicated in adipocytes differentiation, elevated serum free fatty acids, triglycerides, insulin and bile synthesis (Collison et al. 2010b). Authors hypothesized that the development of hepatic insulin resistance could be the consequence of deregulation 
between liver and adipose tissue. In accordance with these results are the findings of elevated aspartate aminotransferase and alanine aminotransferase in adult male Wistar rats treated with $0.04 \mathrm{mg} / \mathrm{kg}$ and $0.08 \mathrm{mg} / \mathrm{kg}$ of monosodium glutamate mixed with the grower's mash for 42 days, with degenerative changes on the liver and dilatation of the central vein (Eweka et al. 2011). Oxidative stress after MSG administration by a gavage at a dose of 0.6 $\mathrm{mg} / \mathrm{g}$ for 10 days has been shown in the liver of rats, in which MSG induced lipid peroxidation, decreased reduced glutathione level and increased activities of glutathiones-transferase, catalase and superoxide dismutase (Onyema et al. 2006).

The studies indicated that MSG diet influenced both hepatic and adipose tissue in both adult (Onyema et al. 2006, RomanRamos et al. 2011) and progeny of female rodents with great impact on offspring metabolism (Afifi and Abbas 2011, Collison et al. 2010b). Interesting finding is the higher abdominal fat and fat body weight in spite of lower daily energy intake and body weight in the offsprings of MSG fed rats than in the offsprings of high caloric chow fed rats (Afifi and Abbas 2011). Similar results concerning fat content/body weight ratio have been observed in 30 days old rats injected with 4 $\mathrm{g} / \mathrm{kg}$ of MSG within the first 10 days of life. Higher adipocyte lipid content, cell diameter, surface area and volume in spite of lower body weight with the results in arrested growth and obesity after MSG administration compared to control rats have been found (Dolnikoff et al. 2001).

The doses and administration of MSG to rodents in other studies designed for obesity, metabolism and liver disturbances research (Collison et al. 2010b, Eweka et al. 2011) are more similar to human MSG intake than in studies focused on MSG effects on the CNS. Animal studies' results could be the link to potential mechanisms of MSG effects on metabolism in humans, however the substantial differences must be noted. The findings of higher body fat weight in spite of lower body weight were not in accordance with human studies in which MSG intake was positively associated with BMI and incidence of overweight in apparently healthy Chinese adults (He et al. 2011). Although the plausibility of the hypothesis of MSG intake in connection with obesity has been discussed (Bursey et al. 2011) and opposite results have been previously found (Shi et al. 2010), the decreased body weight in mice could be associated with the fact that mice neonatally injected with MSG did not become obese until puberty (Dolnikoff et al. 2001). Thus, it is possible that MSG has different effects on the function of adipose tissue in immature individuals and adults.

The other important difference between the outcomes of animal and human studies `are the pathomechanisms potentially leading to obesity. While obesity after MSG diet in rats could be the result of leptin resistance (Dolnikoff et al. 2001), in humans MSG could lead to obesity due to the increase in the intake of high caloric savory foods, in which MSG enhances liking resulting in learning reinforcement (Bannai and Torii 2013, Yeomans et al. 2008). In accordance with this hypothesis is the finding of a significant increase of hunger and savory flavor soup intake, even in the absence of MSG, which has been observed in a group of volunteers previously trained in four sessions where the soup was consumed with added MSG (Yeomans et al. 2008). However, the opposite results including subjective assessments of hunger have been shown in adults supplemented for 6 days with a nutritional dose of MSG (2 g/day). MSG did not affect hunger and fullness of sensations, however it significantly increased gastric distension for 2 hours following the meal. MSG intake was also associated with increased levels of some circulating amino acids (leucine, isoleucine, valine, lysine, cysteine, alanine, tyrosine, and tryptophan) compared with controls. No changes in the postprandial glucose and insulin were noted between MSG and $\mathrm{NaCl}$ supplemented meals used in controls (Boutry et al. 2011), which is a significant difference 
from previously mentioned animal studies. However the insulin response in $75 \mathrm{~min}$ postprandially positively correlated with the plasma glutamate concentration during the oral glucose tolerance test, which indicates that glutamate can participate in the insulin response to nutrients during food intake (Chevassus et al. 2002). The MSG influence on insulin release in humans should be also evaluated immediately after MSG intake, as the efferent pancreatic branch of vagus nerve could stimulate insulin secretion during the cephalic phase after tasting MSG, which was shown in rats (Niijima et al. 1990).

Furthermore, animal studies results are applicable with difficulty to humans as human food is much more diverse, rich and combined with another substances potentially leading to potentiation or inhibition of particular compounds effects. It has been shown, that MSG $(120 \mathrm{mg} / \mathrm{kg} /$ day $)$ in combination with aspartame elevated body weight and caused 2.3-fold increase in fasting blood glucose compared to standard chow and also caused increased insulin resistance during the Insulin Tolerance Test compared to aspartame alone (50 $\mathrm{mg} / \mathrm{kg} /$ day), which caused 1.6-fold increase in fasting blood glucose with reduction of insulin sensitivity during an Insulin Tolerance Test in mice (Collison et al. 2012). MSG combined with dietary trans-fat increased central adiposity and dyslipidemia compared to mice fed with either trans-fatty acids-enriched diet or dietary MSG alone (Collison et al. 2010a).

Inconclusion the animal studies have shown that MSG peroral administration in doses similar to average human intake (Eweka et al. 2011) and the intake in extreme users (Collison et al. 2010b) led to disturbances in metabolism with the increase in more parameters including insulin, fatty acids and triglycerides in serum,it increased the expression of several genes implicated in adipocytes differentiation and it also affected the liver function resulting in elevation of transaminase levels and bile synthesis. However, the application of these results to human MSG intake is difficult due to differences in mechanisms which could potentially lead to obesity and possibile combination with another substances leading to potentiation or inhibition of particular compounds` effects. The contradictions in the results of human studies require further research to evaluate the influence of the dietary MSG intake on obesity, metabolic and gastrointestinal functions.

\section{Chinese Restaurant Syndrome}

The „Chinese restaurant syndrome “(CRS) was for the first time described more than 40 years ago. The original description of symptoms having their onset about 20 minutes after starting the meal included numbness or burning at the back of the neck, radiating into both arms and sometimes into the anterior thorax, which was associated with a feeling of general weakness and palpitation ('Chinese restaurant syndrome' 1968). The symptoms of flushing, dizziness, syncope, and facial pressure were described later (Geha et al. 2000). Monosodium glutamate was widely believed to be associated with CRS, however reviews of relevant studies have proposed that the studies which associated MSG with CRS did not have the robust experimental design, results were inconsistent and the frequency of responses to MSG intake was not high enough to bring evidence that MSG is the trigger of CRS (Zautcke et al. 1986, Freeman 2006). Thus there appears to be little reason to embark on an extensive workup and treatment regimen with a presumptive diagnosis of MSG intoxication (Zautcke et al. 1986). Headaches or other symptoms after Chinese food intake could be rather associated with exceptionally high concentrations of fat and sodium typical for Chinese restaurant meals (Freeman 2006).

After 40 years of research we can conclude that the symptoms of CRS have not been proved to be associated with MSG compound in Chinese food and the prevalence of the typical symptoms is very low. In a questionnaire survey in 1979 including 
3222 respondents only $1-2 \%$ reported symptoms characteristic for CRS and only $0.19 \%$ associated the characteristic symptoms with consumption of Chinese food (Kerr et al. 1979). Moreover, the symptoms experienced by people who reported the sensitivity to MSG, are inconsistent. As Kerr (1979) proposed: „If the word "syndrome" is to be used to describe symptoms attributed to specific food ingredients, the limits of the "syndrome" must be specified." (Kerr et al. 1979). Thus, the particular symptoms of CRS should be studied in double-blind and placebo-controlled conditions to identify MSG possible negative dietary effects. Such study was conducted to investigate headache, pain and mechanical sensitivity in pericranial muscles after oral administration of MSG (75 or $150 \mathrm{mg} / \mathrm{kg}$ ) or $\mathrm{NaCl}$ (24 mg/kg, placebo). No muscle pain or changes in mechanical sensitivity have been detected. However, reports of headache and tenderness of pericranial muscle increased after MSG, furthermore elevation of systolic blood pressure has been observed in the MSG session with $150 \mathrm{mg} / \mathrm{kg}$ compared with MSG $75 \mathrm{mg} / \mathrm{kg}$ and placebo (Baad-Hansen et al. 2010). Thus, although it is not probable that intake of MSG is specifically connected to the complex CRS, MSG could produce particular symptoms which are or are not a part of the original description of CRS.

\section{Reproductive Organs}

The effects of MSG on the reproductive system are documented in a smaller number than the effects previously mentioned and to our best knowledge they are limited only to animal studies. In male Swiss Albino mice subcutaneous administration of MSG at a dose of $2 \mathrm{mg} / \mathrm{g}$ during the perinatal period at the $2 \mathrm{nd}, 4 \mathrm{th}, 6 \mathrm{th}, 8 \mathrm{th}$ and 10 th days of life lead to the increase in the number of the pachytene stage of primary spermatocyte at the 75th day of life compared to controls (Das and Ghosh 2010). The double dose (4 $\mathrm{mg} / \mathrm{g}$ ) of MSG administered at the same time to newborn rats resulted in the decreased weight of pituitary glands and testes and lowered testosterone level in 4 months old sexually mature male rats (Miskowiak et al. 1993). In female Swiss Albino mice, subcutaneous injection of MSG (2 mg/g) at the same perinatal period $(2 \mathrm{nd}, 4 \mathrm{th}, 6 \mathrm{th}, 8 \mathrm{th}$ and 10th day of life) led to increased number of the primary follicles without any increase in number of Graffian follicles in ovarian tissue at the 75th day of life (Das and Ghosh 2011).

Great limitation of these studies is the subcutaneous application and period of MSG administration which makes the results hardly applicable to human medicine. From this point of view, more important are the studies in which MSG was mixed with the grower's mash in adults. In adult female Wistar rats fed by MSG at the doses of 0.04 $\mathrm{mg} / \mathrm{kg}$ or $0.08 \mathrm{mg} / \mathrm{kg}$ on a daily basis the pathological changes have been observed in ovaries (Eweka and Om'iniabohs 2011) and fallopian tube (Eweka et al. 2010). MSG caused cellular hypertrophy of the theca folliculi, destruction of the basement membrane and stroma cells' vacuolations in the ovaries. Degenerative and atrophic processes were observed at both doses with more pronounced changes in the group treated with higher dose $(0.08 \mathrm{mg} / \mathrm{kg})$ of MSG (Eweka and Om'iniabohs 2011). Similarly in fallopian tube, both MSG doses caused distortion of the basement membrane with the separation of the endosalpinx from the myosalpinx, however in rats taking 0.08 $\mathrm{mg} / \mathrm{kg}$, vacuolations and lysed red blood cells appeared in some parts of the stroma cells (Eweka et al. 2010). Although these studies have shown the effects of MSG on female reproductive organs in relevant doses after peroral intake, further studies must be done to corroborate these results and to explore the ingested MSG effects also on male sex organs.

\section{Other MSG Effects}

MSG intake and its deleterious effects have been proposed also in the connection with several other systems. One of the most extensive discussions has been directed to MSG as a trigger of asthma. Although there 
are a few anecdotal reports of MSG sensitivity linked to asthma, reviews have shown that these studies did not have the robust experimental design and were not reproducible to bring the evidence that MSG is related to asthma response (Freeman 2006, Beausoleil et al. 2007). Also the newer study about the dietary patterns and MSG intake has failed to prove the connection between MSG and asthma in Chinese adults (Shi et al. 2012b). Moreover, there is no evidence to support the avoidance of MSG in adults with chronic asthma (Zhou et al. 2012), which is supported by an animal study of an ovalbumin-induced asthma mouse model fed with a diet containing $0.5 \%$ or 5\% MSG the week before the first ovalbumin injection and for the subsequent 3-week period, in which MSG did not have the influence on eosinophil infiltration, production of Th2 cytokines and circulating IgE concentrations in the lungs and did not affect the induced airway hyperresponsiveness (Yoneda et al. 2011).

Several studies have brought evidence about the associations between MSG-induced obesity and other systems. The injections of MSG in the first 7 days of life leading to MSGinduced obesity resulted in the increase of mean arterial blood pressure and reduction of heart rate variability, bradycardic responses, vagal and sympathetic effects at 33 weeks compared to control rats (Konrad et al. 2012).

Mice obesity model induced by MSG has shown a significantly greater fall in core temperature after acute cold exposure (4 degrees $\mathrm{C}$ for two hours) and did not mobilize brown adipose tissue lipids after exposure to 4 degrees Celsius for six hours whereas control animals did. The authors proposed that MSG-treated mice had defective cold induced thermogenesis, which could result from impaired activation of thermogenic mechanisms in brown adipose tissue (Moss et al. 1985).

A human study evaluating the relationship between MSG and hemoglobin in 1197
Chinese men and women has found a positive association between MSG intake and hemoglobin increase only in men. The authors hypothesized that MSG effect could be mediated via leptin due to the potential role of leptin in hematopoiesis (Shi et al. 2012a).

Studies indicate that MSG influences are complex and its effects on particular system lead to the changes in the other system. Further research should be focused on changes in various systems and their communication evoked by MSG intake in nutritional doses in men and women.

\section{Prevention of MSG Toxic Effects}

The studies which brought the evidence about the deleterious effects of MSG administration led to further research of potential protective effects of different molecules, especially antioxidants.

Vitamin $C$ in a dose $100 \mathrm{mg} / \mathrm{kg} /$ day given via a metal orogastric tube simultaneously with MSG at a dose of $3 \mathrm{~g} / \mathrm{kg} /$ day mixed with foods for 14 days has been shown to have a protective role against toxic nerve cell and astrocyte glial fibrillary acidic protein damage in cerebellar cortex in male albino rats (Hashem et al. 2012). All vitamin C $(200 \mathrm{mg} / \mathrm{kg})$, vitamin E $(200 \mathrm{mg} / \mathrm{kg})$ and quercetin $(10 \mathrm{mg} / \mathrm{kg})$ given perorally were effective in reduction of the MSG-induced increase in malondialdehyde, modulated gluthatione levels and glutathione-Stransferase activity and were effective in ameliorating the effects of MSG on the superoxide dismutase and catalase activity in the liver, kidney and brain in MSG-treated rats $(4 \mathrm{mg} / \mathrm{g}$, intraperitoneally for 10 days). All antioxidants reduced MSG-increase in serum alanine aminotransferase, aspartate aminotransferase and $\gamma$-glutamyl transferase (Farombi and Onyema 2006). Similar results have been found in the study of vitamin $\mathrm{E}$ effects in rats fed by MSG at a dose $0.6 \mathrm{mg} / \mathrm{g}$ by gavage. Vitamin E $(0.2 \mathrm{mg} / \mathrm{g})$ significantly reduced the lipid peroxidation, it increased the glutathione level and decreased the 
hepatic activities of glutathione-stransferase, catalase and superoxide dismutase in liver. The activities of alanine aminotransferase, aspartate aminotransferase and $\gamma$-glutamyl transferase in serum were also significantly reduced (Onyema et al. 2006).

Quercetin $(75 \mathrm{mg} / \mathrm{kg}$, administered in 30 day-old male Wistar rats over 42 days) has been shown to normalize HDLcholesterol, reduce insulin, leptin, glucose and creatinine levels and increased glutathione peroxidase and superoxide dismutase activities after MSG subcutaneous application ( $4 \mathrm{mg} / \mathrm{g}$ administered in neonatal rats from 2. to 12.day) (Seiva et al. 2012).

Protective effects of pretreatment with diltiazem from the development of morphological and functional disorders in ovaries have been shown in female rat pups treated with MSG (Bojanic et al. 2009).

\section{Conclusions}

Monosodium glutamate (MSG) is one of the world's most widely used food additives which enhances the flavor of food. MSG toxic effects on central nervous system, adipose tissue, hepatic tissue and reproductive organs were shown in numerous animal studies, however the method of administration and the used doses in most of them were not comparable with human MSG intake. Animal studies in which MSG was administered perorally in doses similar to average human intake or intake of extreme users showed that MSG led to disturbances in metabolism with the increase in more parameters including insulin, fatty acids and triglycerides in serum, MSG increased the expression of several genes implicated in adipocytes differentiation, it affected the liver function resulting in elevation of transaminases' levels and bile synthesis, it also led to oxidative stress in liver and to the pathological changes in ovaries and fallopian tube. MSG intake in human studies was associated with increased levels of several circulating amino acids, however no changes in the postprandial glucose and insulin were found, which was in contradiction to animal studies` results.The relationship between MSG and increased hemoglobin was shown in men and MSG intake was associated with headache and subjectively reported pericranial muscle tenderness. Chinese restaurant syndrome and asthma were not proved to be associated with MSG intake. Vitamin C, vitamin E, quercetin and diltiazem had protective effects on MSG-induced toxic changes.

\section{Acknowledgement}

The work was supported by grant APVV0254-11.

\section{References}

Afifi, M. M. \& Abbas, A. M. (2011). "Monosodium Glutamate versus Diet Induced Obesity in Pregnant Rats and Their Offspring," Acta Physiologica Hungarica, 98(2), 177-88.

Ali, M. M., Bawari, M., Misra, U. K. \& Babu, G. N. (2000). "Locomotor and Learning Deficits in Adult Rats Exposed to Monosodium-LGlutamate during Early Life," Neuroscience Letters, 284(1-2), 57-60.

Baad-Hansen, L., Cairns, B., Ernberg, M. \& Svensson, P. (2010). "Effect of Systemic Monosodium Glutamate (MSG) on Headache and Pericranial Muscle Sensitivity," Cephalalgia, 30(1), 68-76.

Bannai, M. \& Torii, K. (2013). "Digestive Physiology of the Pig Symposium: Detection of Dietary Glutamate via Gut-Brain Axis," Journal of Animal Science, 91(5), 1974-81.

Beausoleil, J. L., Fiedler, J. \& Spergel, J. M. (2007). "Food Intolerance and Childhood Asthma: What is the Link?," Paediatric Drugs, 9(3), 157-63.

Beyreuther, K., Biesalski, H. K., Fernstrom, J. D., Grimm, P., Hammes, W. P., Heinemann, U., 
Kempski, O., Stehle, P., Steinhart, H. \& Walker, R. (2007). "Consensus Meeting: Monosodium Glutamate - An Update," European Journal of Clinical Nutrition, 61(3), 304-13.

Blanks, J. C., Reif-Lehrer, L. \& Casper, D. (1981). "Effects of Monosodium Glutamate on the Isolated Retina of the Chick Embryo as a Function of Age: A Morphological Study," Experimental Eye Research, 32(1), 105-24.

Bojanic, V., Bojanic, Z., Najman, S., Savic, T., Jakovljevic, V., Najman, S. \& Jancic, S. (2009). "Diltiazem Prevention of Toxic Effects of Monosodium Glutamate on Ovaries in Rats," General Physiology and Biophysics, 28 Spec No, 149-54.

Boutry, C., Matsumoto, H., Airinei, G., Benamouzig, R., Tome, D., Blachier, F. \& Bos, C. (2011). "Monosodium Glutamate Raises Antral Distension and Plasma Amino Acid after a Standard Meal in Humans," American Journal of Physiology - Gastrointestinal and Liver Physiology, 300(1), G137-45.

Bursey, R. G., Watson, L. \& Smriga, M. (2011). "A Lack of Epidemiologic Evidence to Link Consumption of Monosodium L-Glutamate and Obesity in China," The American Journal of Clinical Nutrition, 94(3), 958-60; author reply 960-1.

Chevassus, H., Renard, E., Bertrand, G., Mourand, I., Puech, R., Molinier, N., Bockaert, J., Petit, P. \& Bringer, J. (2002). "Effects of Oral Monosodium (L)-Glutamate on Insulin Secretion and Glucose Tolerance in Healthy Volunteers," British Journal of Clinical Pharmacology, 53(6), 641-3.

'Chinese Restaurant Syndrome,' (1968) Can Med Assoc J, 99(24), 1206-7.

Collison, K. S., Makhoul, N. J., Inglis, A., Al-Johi, M., Zaidi, M. Z., Maqbool, Z., Saleh, S. M., Bakheet, R., Mondreal, R., Al-Rabiah, R., Shoukri, M., Milgram, N. W. \& Al-Mohanna, F. A. (2010a). "Dietary Trans-Fat Combined with Monosodium Glutamate Induces
Dyslipidemia and Impairs Spatial Memory," Physiology \& Behavior, 99(3), 334-42.

Collison, K. S., Makhoul, N. J., Zaidi, M. Z., AlRabiah, R., Inglis, A., Andres, B. L., Ubungen, R., Shoukri, M. \& Al-Mohanna, F. A. (2012). "Interactive Effects of Neonatal Exposure to Monosodium Glutamate and Aspartame on Glucose Homeostasis," Nutrition \& Metabolism (Lond), 9(1), 58.

Collison, K. S., Maqbool, Z. M., Inglis, A. L., Makhoul, N. J., Saleh, S. M., Bakheet, R. H., AlJohi, M. A., Al-Rabiah, R. K., Zaidi, M. Z. \& AlMohanna, F. A. (2010b). "Effect of Dietary Monosodium Glutamate on HFCS-Induced Hepatic Steatosis: Expression Profiles in the Liver and Visceral Fat," Obesity (Silver Spring), 18(6), 1122-34.

Das, R. S. \& Ghosh, S. K. (2010). "Long Term Effects of Monosodium Glutamate on Spermatogenesis Following Neonatal Exposure in Albino Mice--A Histological Study," Nepal Medical College Journal, 12(3), 149-53.

Das, R. S. \& Ghosh, S. K. (2011). "Long-Term Effects in Ovaries of the Adult Mice Following Exposure to Monosodium Glutamate during Neonatal Life--A Histological Study," Nepal Medical College Journal, 13(2), 77-83.

Dolnikoff, M., Martin-Hidalgo, A., Machado, U. F., Lima, F. B. \& Herrera, E. (2001). "Decreased Lipolysis and Enhanced Glycerol and Glucose Utilization by Adipose Tissue Prior to Development of Obesity in Monosodium Glutamate (MSG) TreatedRats," International Journal of Obesity, 25(3), 426-33.

Eweka, A. O., Eweka, A. \& Om'iniabohs, F. A. E. (2010). "Histological Studies of the Effects of Monosodium Glutamate of the Fallopian Tubes of Adult Female Wistar Rats," North American Journal of Medical Sciences, 2(3), 146-9.

Eweka, A. O., Igbigbi, P. S. \& Ucheya, R. E. (2011). "Histochemical Studies of the Effects 
of Monosodium Glutamate on the Liver of Adult Wistar Rats," Annal of Medical \& Health Sciences Research, 1(1), 21-9.

Eweka, A. O. \& Om'iniabohs, F. A. E.. (2011). "Histological Studies of the Effects of Monosodium Glutamate on the Ovaries of Adult Wistar Rats," Annal of Medical \& Health Sciences Research, 1(1), 37-43.

Farombi, E. O. \& Onyema, O. O. (2006). "Monosodium Glutamate-Induced Oxidative Damage and Genotoxicity in the Rat: Modulatory Role of Vitamin C, Vitamin E and Quercetin," Hum Exp Toxicol, 25(5), 251-9.

Freeman, M. (2006). "Reconsidering the Effects of Monosodium Glutamate: A Literature Review," Journal of the American Academy of Nurse Practitioners, 18(10), 4826.

Geha, R. S., Beiser, A., Ren, C., Patterson, R., Greenberger, P. A., Grammer, L. C., Ditto, A. M., Harris, K. E., Shaughnessy, M. A., Yarnold, P. R., Corren, J. \& Saxon, A. (2000). "Review of Alleged Reaction to Monosodium Glutamate and Outcome of a Multicenter Double-Blind Placebo-Controlled Study," The Journal of Nutrition, 130(4S Suppl), 1058S-62S.

Gonzalez-Burgos, I., Perez-Vega, M. I. \& BeasZarate, C. (2001). "Neonatal Exposure to Monosodium Glutamate Induces Cell Death and Dendritic Hypotrophy in Rat Prefrontocortical Pyramidal Neurons," Neuroscience Letters, 297(2), 69-72.

Hashem, H. E., El-Din Safwat, M. D. \& Algaidi, S. (2012). "The Effect of Monosodium Glutamate on the Cerebellar Cortex of Male Albino Rats and the Protective Role of Vitamin C (Histological and Immunohistochemical Study)," Journal of Molecular Histology, 43(2), 179-86.

He, K., Du, S., Xun, P., Sharma, S., Wang, H., Zhai, F. \& Popkin, B. (2011). "Consumption of Monosodium Glutamate in Relation to Incidence of Overweight in Chinese Adults: China Health and Nutrition Survey (CHNS),"
The American Journal of Clinical Nutrition, 93(6), 1328-36.

Hermanussen, M. \& Tresguerres, J. A. F. (2003). "Does High Glutamate Intake Cause Obesity?," Journal of Pediatric Endocrinology and Metabolism, 16(7), 965-8.

Hyndman, A. G. \& Adler, R. (1981). “Analysis of Glutamate Uptake and Monosodium Glutamate Toxicity in Neural Retina Monolayer Cultures," Developmental Brain Research, 254(2), 303-14.

Kerr, G. R., Wu-Lee, M., El-Lozy, M., McGandy, R. \& Stare, F. J. (1979). "Prevalence of the "Chinese Restaurant Syndrome"," Journal of American Dietetic Association, 75(1), 29-33.

Konrad, S. P., Farah, V., Rodrigues, B., Wichi, R. B., Machado, U. F., Lopes, H. F., D'Agord Schaan, B., De Angelis, K. \& Irigoyen, M. C. (2012). "Monosodium Glutamate Neonatal Treatment Induces Cardiovascular Autonomic Function Changes in Rodents," Clinics (Sao Paulo), 67(10), 1209-14.

Mattson, M. P. (2008). "Glutamate and Neurotrophic Factors in Neuronal Plasticity and Disease," Annals of the New York Academy of Sciences, 1144, 97-112.

Matyskova, R., Maletinska, L., Maixnerova, J., Pirnik, Z., Kiss, A. \& Zelezna, B. (2008). "Comparison of the Obesity Phenotypes Related to Monosodium Glutamate Effect on Arcuate Nucleus and/or the High Fat Diet Feeding in C57BL/6 and NMRI Mice," Physiological Research, 57(5), 727-34.

Meldrum, B. S. (2000). "Glutamate as a Neurotransmitter in the Brain: Review of Physiology and Pathology," Journal of Nutrition, 130(4S Suppl), 1007S-15S.

Miskowiak, B., Limanowski, A. \& Partyka, M. (1993). "[Effect of Perinatal Administration of Monosodium Glutamate (MSG) on the Reproductive System of the Male Rat]," Endokrynologia Polska, 44(4), 497-505. 
Miskowiak, B. \& Partyka, M. (2000). "Neonatal Treatment with Monosodium Glutamate (MSG): Structure of the TSHImmunoreactive Pituitary Cells," Histology and Histopathology, 15(2), 415-9.

Moss, D., Ma, A. \& Cameron, D. P. (1985). "Defective Thermoregulatory Thermogenesis in Monosodium Glutamate-Induced Obesity in Mice," Metabolism, 34(7), 626-30.

Niijima, A., Togiyama, T. \& Adachi, A. (1990). "Cephalic-Phase Insulin Release Induced by Taste Stimulus of Monosodium Glutamate (Umami Taste)," Physiology \& Behavior, 48(6), 905-8.

Onyema, O. O., Farombi, E. O., Emerole, G. O., Ukoha, A. I. \& Onyeze, G. O. (2006). "Effect of Vitamin $\mathrm{E}$ on Monosodium Glutamate Induced Hepatotoxicity and Oxidative Stress in Rats," Indian Journal of Biochemestry \& Biophysics, 43(1), 20-4.

Pelaez, B., Blazquez, J. L., Pastor, F. E., Sanchez, A. \& Amat, P. (1999). "Lectinhistochemistry and Ultrastructure of Microglial Response to Monosodium Glutamate-Mediated Neurotoxicity in the Arcuate Nucleus," Histology and histopathology, 14(1), 165-74.

Reeds, P. J., Burrin, D. G., Jahoor, F., Wykes, L., Henry, J. \& Frazer, E. M. (1996). "Enteral Glutamate is almost Completely Metabolized in First Pass by the Gastrointestinal Tract of Infant Pigs," American Journal of Physiology, 270(3 Pt 1), E413-8.

Regan, J. W., Roeske, W. R., Ruth, W. H., Deshmukh, P. \& Yamamura, H. I. (1981). "Reductions in Retinal Gamma-Aminobutyric Acid (GABA) Content and in [3H]Flunitrazepam Binding after Postnatal Monosodium Glutamate Injections in Rats," Journal of Pharmacology and Experimental Therapeutics, 218(3), 791-6.

Reif-Lehrer, L., Bergenthal, J. \& Hanninen, L. (1975). "Effects of Monosodium Glutamate on Chick Embryo Retina in Culture,"
Investigative Ophthalmologyb\& Visual Science, 14(2), 114-24.

Rhodes, J., Titherley, A. C., Norman, J. A., Wood, R. \& Lord, D. W. (1991). "A Survey of the Monosodium Glutamate Content of Foods and an Estimation of the Dietary Intake of Monosodium Glutamate," Food Additives \& Contaminants, 8(5), 663-72.

Rivera-Cervantes, M. C., Torres, J. S., FeriaVelasco, A., Armendariz-Borunda, J. \& BeasZarate, C. (2004). "NMDA and AMPA Receptor Expression and Cortical Neuronal Death are Associated with p38 in GlutamateInduced Excitotoxicity in Vivo," Journal of Neuroscience Research, 76(5), 678-87.

Roman-Ramos, R., Almanza-Perez, J. C., Garcia-Macedo, R., Blancas-Flores, G., FortisBarrera, A., Jasso, E. I., Garcia-Lorenzana, M., Campos-Sepulveda, A. E., Cruz, M. \& AlarconAguilar, F. J. (2011). "Monosodium Glutamate Neonatal Intoxication Associated with Obesity in Adult Stage is Characterized by Chronic Inflammation and Increased mRNA Expression of Peroxisome ProliferatorActivated Receptors in Mice," Basic \& Clinical Pharmacology \& Toxicology, 108(6), 406-13.

Seiva, F. R. F., Chuffa, L. G. A., Braga, C. P., Amorim, J. P. A. \& Fernandes, A. A. H. (2012). "Quercetin Ameliorates Glucose and Lipid Metabolism and Improves Antioxidant Status in Postnatally Monosodium GlutamateInduced Metabolic Alterations," Food and Chemical Toxicology, 50(10), 3556-61.

Shi, Z., Luscombe-Marsh, N. D., Wittert, G. A., Yuan, B., Dai, Y., Pan, X. \& Taylor, A. W. (2010). "Monosodium Glutamate is not Associated with Obesity or a Greater Prevalence of Weight Gain over 5 Years: Findings from the Jiangsu Nutrition Study of Chinese Adults," British Journal of Nutrition, 104(3), 457-63.

Shi, Z., Yuan, B., Taylor, A. W., Dal Grande, E. \& Wittert, G. A. (2012a). "Monosodium Glutamate Intake Increases Hemoglobin 
Level over 5 Years among Chinese Adults," Amino Acids, 43(3), 1389-97.

Shi, Z., Yuan, B., Wittert, G. A., Pan, X., Dai, Y., Adams, R. \& Taylor, A. W. (2012b). "Monosodium Glutamate Intake, Dietary Patterns and Asthma in Chinese Adults," PLoS One, 7(12), e51567.

Skultetyova, I., Kiss, A. \& Jezova, D. (1998). "Neurotoxic Lesions Induced by Monosodium Glutamate Result in Increased Adenopituitary Proopiomelanocortin Gene Expression and Decreased Corticosterone Clearance in Rats," Neuroendocrinology, 67(6), 412-20.

Takasaki, Y. (1978). "Studies on Brain Lesions after Administration of Monosodium L-Glutamate to Mice. II. Absence of Brain Damage Following Administration of Monosodium L-Glutamate in the Diet," Toxicology, 9(4), 307-18.

Walker, R. \& Lupien, J. R. (2000). "The Safety Evaluation of Monosodium Glutamate," Journal of Nutrition, 130(4S Suppl), 1049S$52 \mathrm{~S}$.

Yeomans, M. R., Gould, N. J., Mobini, S. \& Prescott, J. (2008). "Acquired Flavor Acceptance and Intake Facilitated by Monosodium Glutamate in Humans," Physiology \& Behavior, 93(4-5), 958-66.

Yoneda, J., Chin, K., Torii, K. \& Sakai, R. (2011). "Effects of Oral Monosodium Glutamate in Mouse Models of Asthma," Food and Chemical Toxicology, 49(1), 299-304.

Yu, T., Zhao, Y., Shi, W., Ma, R. \& Yu, L. (1997). "Effects of Maternal Oral Administration of Monosodium Glutamate at a Late Stage of Pregnancy on Developing Mouse Fetal Brain," Brain Research, 747(2), 195-206.

Zautcke, J. L., Schwartz, J. A. \& Mueller, E. J. (1986). "Chinese Restaurant Syndrome: A Review," Annals of Emergency Medicine, 15(10), 1210-3.
Zhou, Y., Yang, M. \& Dong, B. R. (2012). "Monosodium Glutamate Avoidance for Chronic Asthma in Adults and Children," Cochrane Database Systematic Reviews, 6, CD004357. 